Published in final edited form as:

Cogn Emot. 2011 April ; 25(3): 400-412. doi:10.1080/02699931.2010.544160.

\title{
Explicit and Implicit Emotion Regulation: A Dual-Process Framework
}

\author{
Anett Gyurak ${ }^{1,2,3}$, James J. Gross ${ }^{2}$, and Amit Etkin ${ }^{1,3}$ \\ ${ }^{1}$ Department of Psychiatry and Behavioral Sciences, Stanford University, Stanford, CA \\ ${ }^{2}$ Department of Psychology, Stanford University, Stanford, CA \\ ${ }^{3}$ Sierra-Pacific Mental IIIness, Research, Education, and Clinical Center (MIRECC), Veterans \\ Affairs Palo Alto Health Care System, Palo Alto, CA
}

\begin{abstract}
It is widely acknowledged that emotions can be regulated in an astonishing variety of ways. Most research to date has focused on explicit (effortful) forms of emotion regulation. However, there is growing research interest in implicit (automatic) forms of emotion regulation. To organize emerging findings, we present a dual-process framework that integrates explicit and implicit forms of emotion regulation, and argue that both forms of regulation are necessary for well-being. In the first section of this review, we provide a broad overview of the construct of emotion regulation, with an emphasis on explicit and implicit processes. In the second section, we focus on explicit emotion regulation, considering both neural mechanisms that are associated with these processes and their experiential and physiological consequences. In the third section, we turn to several forms of implicit emotion regulation, and integrate the burgeoning literature in this area. We conclude by outlining open questions and areas for future research.
\end{abstract}

There are virtually endless ways of managing unwanted and distracting emotions. Research on emotion regulation has historically focused on effortful (explicit) attempts to alter the course and intensity of emotional responses. More recently, researchers have started to describe less effortful and more automatic (implicit) forms of emotion regulation. Using a dual-process model as a framework, our goal in this paper is to review and integrate existing research on explicit and implicit emotion regulation, and outline future work aimed at linking these two approaches. Our aim is not to provide a comprehensive review of emotion regulation as a field (for reviews see: Gross,1998a; Gross \& Thompson, 2007; Koole, 2010). Rather, our aim is to present a framework that is useful for integrating research on explicit and implicit emotion, thus choice of findings is therefore strategic rather than exhaustive.

\section{Defining Emotion Regulation}

The importance of regulating emotional impulses in general, and anxiety in particular, was highlighted by early psychological theorizing, dating back to Sigmund Freud, who made anxiety-regulation the centerpiece of the psychodynamic theory of mental life (S. Freud, 1926; see also A. Freud, 1936). This early work was extended by researchers in the stress and coping tradition, who explored cognitive and behavioral strategies aimed at managing specific external and/or internal demands that are appraised as stressful, and taxing or exceeding the resources of the person (Lazarus \& Folkman, 1984).

Address correspondence to Anett Gyurak, Department of Psychiatry, 401 Quarry Road, MC: 5797, Stanford, CA 94305-5797. agyurak@ stanford.edu. Phone: +1 650.493.5000 ext: (1) (1) 63029. 
Developmental researchers have also long recognized the relationship between emotion regulatory abilities and adjustment, and emphasized self- and emotion-regulation as a correlate of social and emotional functioning in children (J. J. Campos, R. G. Campos, \& Barrett, 1989; Cole, Martin, \& Dennis, 2004; Posner \& Rothbart, 2003). Studies of emotion regulation in this tradition span from infancy (Campos et al., 1989; Posner \& Rothbart, 2003), through childhood (Eisenberg, Fabes, Guthrie, \& Reiser, 2000), into adolescence (Lewis, Lamm, Segalowitz, Stieben, \& Zelazo, 2006) and old age (Gross et al., 1997).

In the past decade or so, the field of emotion regulation has come into its own (Gross, 1998a). Researchers interested in emotion regulation have generally viewed emotions as whole-body responses that signal personally relevant, motivationally significant events (Frijda, 1987; Levenson, 1999). From this perspective, emotion regulation may be defined as goal directed processes functioning to influence the intensity, duration and type of emotion experienced (Gross \& Thompson, 2007). Emotion regulation permits flexibility in emotional responding in accord with one's momentary as well as one's longer-term goals in any given situation.

A variety of classification systems exist for emotion regulatory processes. For example, Gross's (e.g., Gross, 1998a) process model of emotion regulation highlights the time course of emotion regulation. By contrast, Koole (2010) has emphasized motivational-functional dimensions in organizing the literature.

In the present paper, we aim to illustrate the ways in which explicit (often called effortful) and implicit (often called automatic) processes cut across and organize the existing literature. The difficulty in proposing an integrative model of emotion regulation is highlighted more generally by the controversies surrounding other dual-process conceptualizations (Bargh, 1994; Moors \& De Houwer, 2006). Similar challenges exist when applying an effortful versus automatic dissociation to the field of emotion regulation (Bargh \& Williams, 2007). Encouraged by Bargh and Williams (2007), we choose to benefit from the "hard-earned knowledge gained from the study of automaticity in social cognition" (p. 433) and define two theoretical and empirical spheres that organize different areas of emotion regulation and label these as "explicit" and "implicit." Furthermore, we define explicit emotion regulation as those processes that require conscious effort for initiation and demand some level of monitoring during implementation, and are associated with some level of insight and awareness. Implicit processes are believed to be evoked automatically by the stimulus itself and run to completion without monitoring and can happen without insight and awareness.

Figure 1 captures our conceptualization and depicts how, in our view, explicit and implicit forms of emotion regulation form distinct, yet somewhat inter-related islands of research. Explicit emotion regulation research is positioned in the middle because researchers have repeatedly tested and confirmed that it fits our definition of explicitness (i.e., requires monitoring during implementation and demands some level of insight and awareness). Often when people are faced with an emotion regulatory challenge, the conscious, effortful, rulebased operations of explicit emotion regulatory processes are necessary to adjust initial reactions. Viewed this way, explicit regulation is clearly not something one can effectively engage in all of the time. Rather, given the high demand for moment-to-moment emotion regulation in everyday life, use of efficient implicit emotion regulation processes, which run without awareness, is critical for wellbeing.

Furthermore explicit/implicit regulation are not mutually exclusive categories, but rather have porous boundaries (denoted by the dashed line that surround each box). That is processes may vary in explicitness or implicitness over time or across situations and 
adaptive emotional responses depend on the interplay between explicit and implicit processing - a relationship that is denoted by the double arrows that link explicit and implicit forms of regulation.

In drawing attention to qualities of explicitness and implicitness in the field of emotion regulation, we hope our conceptual framework will inspire others to directly examine how explicit or implicit their particular emotion regulatory process under study is, and relate it to our broader framework. As such, we expect that, with additional research, our model will become increasingly refined and better-characterized - developments we would greatly welcome.

\section{Explicit Emotion Regulation}

A paradigmatic case of explicit regulation may be found in work by James Gross and colleagues (Gross \& Levenson, 1993; McRae et al., 2010; Ochsner, Bunge, Gross, \& Gabrieli, 2002). In a typical test of explicit emotion regulation, participants are presented with a task that involves processing stimuli under two different conditions - one in which participants are instructed to react naturally (reactivity trial), and another in which participants are instructed to regulate their emotional responses (regulation trial) using a strategy specified by the researcher, and which the participant has had ample opportunity to practice beforehand. A schematic description of the task can be seen in Figure 2. Explicit emotion regulation performance is indexed by contrasting emotional responding in the reactivity and regulation trials.

This basic paradigm has been widely adopted, and the body of evidence from these studies suggests that explicit emotion regulation strategies can reliably influence emotional responding. Typically, negative or aversive images are used to elicit emotional responses including negative photographs depicting threat-related images such as accident scenes (e.g., McRae et al., 2010; Ochsner et al., 2002; Ray et al., 2005; Urry, 2010), or disgust-eliciting film excerpts (Goldin, McRae, Ramel, \& Gross, 2008). Other researchers have used positive stimuli in the form of erotica (Beauregard, Lévesque, \& Bourgouin, 2001) or pictures of cute pets and sporting events (Kim \& Hamann, 2007). Most commonly, researchers have studied the effects of down-regulation instructions, using a wide range of strategies, but emotion amplification through up-regulation instructions has also been examined (e.g., Demaree et al., 2006; Eippert et al., 2007; Kunzmann, Kupperbusch, \& Levenson, 2005).

As outlined in our process model of emotion regulation (Gross, 1998b), researchers have instructed participants to engage explicit down regulatory efforts at various points in the emotion generative process. The majority of these studies instructed participants to use reappraisal (change the way they think about the stimuli in order to reduce negative feelings; e.g., Gross, 1998b; Ochsner et al., 2002). In other studies, participants were instructed to distract themselves (Kalisch, Wiech, Herrmann, \& Dolan, 2006; McRae et al., 2010), to employ attentional control (Urry, 2010), to realistically evaluate the stimuli (Herwig et al., 2007), to distance themselves from the negative stimuli (Kalisch et al., 2005) or to use suppression and hide their emotions so that someone watching them would not know what they are feeling (Gross \& Levenson, 1993; Levesque et al., 2003).

According to the process model of emotion regulation (Gross \& Thompson, 2007), interjecting regulation relatively early on in the emotion-generative process appears to be most successful in altering the course of the response (e.g., distraction and attentional control). Similarly, cognitive reappraisal, a strategy typically engaged before full-blown emotional responses develop is more successful in altering the emotional response than suppression, a response focused strategy functioning to prevent emotional responses from being overtly expressed (Gross, 1998b). 
Neuroimaging studies (for a reviews see Ochsner \& Gross, 2005, Kalisch, 2009) show that explicit emotion regulation results in a dynamic interchange between frontal-lobe areas implicated in cognitive control and executive function, and emotion-reactivity areas. Specifically, imaging studies indicate that attempts to reappraise negative stimuli result in increased activation in ventrolateral and dorsolateral prefrontal cortex (PFC) areas traditionally implicated in non-emotional forms of cognitive control (Ochsner et al., 2002). This frontal lobe activation in turn is related to reduced activation in limbic emotionreactivity related areas (amygdala and insula), suggesting that engagement of control-related areas dampens reactivity in these critical emotion-reactivity regions (Banks, Eddy, Angstadt, Nathan, \& Phan, 2007; Goldin, McRae, Ramel, \& Gross, 2008; Ochsner et al., 2002; Wager, M. L. Davidson, Hughes, Lindquist, \& Ochsner, 2008). Interestingly, attempts to engage suppression, a late-stage emotion-regulatory strategy, also engage frontal-lobe areas suggesting that explicit attempts to suppress emotional responses rely on the same areas that reappraisal attempts do, but fail to reduce limbic system activation the same way reappraisal does (Goldin et al., 2008). This result is clearly consistent with autonomic nervous system activation studies that indicate that suppression has an effect on overt displays of emotions but does not alter emotional reactivity (Gross \& Levenson, 1993).

The experimental tasks described here fit our definition of explicit emotion regulation because the process is instructed, effortful, and is carried out with considerable awareness. Specifically, the emotion regulation process described here is an example of explicit regulation, because (a) individuals are aware of the cues that elicited emotional responses (i.e., images, films), (b) aware of the emotions itself (i.e., report reduction in accompanying feelings), and are (c) aware of the effect of the regulation on their behavior (i.e., if prompted, can report back having engaged in emotion regulation).

\section{Beyond Explicit Emotion Regulation}

In this section, we broaden our focus by considering the emerging literature on five important non-explicit forms of emotion regulation. We categorize these research areas in shades of implicitness as there are automatic, routinized components to all. We note that more research is needed to systematically investigate explicit and implicit qualities in these processes.

\section{Emotional Conflict Adaptation}

Our first case of implicit emotion regulation is based on the emotional conflict task described by Etkin and colleagues (Egner, Etkin, Gale, \& Hirsch, 2008; Etkin, Egner, Peraza, Kandel, \& Hirsch, 2006). The task is a variant of the classic Stroop paradigm (Stroop, 1935), and takes advantage of a variant of the congruency sequence effects originally reported by Gratton et al. in non-emotional conflict tasks (Botvinick, Nystrom, Fissell, Carter, \& Cohen, 1999; Gratton, Coles, \& Donchin, 1992). In this task (Figure 3), participants are presented with photographs of emotional faces (fearful or happy) with a word ("fear" or "happy") written over them. The task is to indicate whether the facial expression is happy or fearful by pressing a button. The word written on the photo either matches the facial expression (no-conflict trials: happy face with the word happy written over it, or fearful face with the word fear written over it), or is incongruent with the facial expression (conflict trials: happy face with the word fear written over it, or fearful face with the word happy written over it).

Because reading is automatized (Stroop, 1935), during conflict trials participants need to enact control over reading the word in favor of labeling the emotional expression. Consistent with this, conflict trials take longer to respond to as compared to no-conflict trials; this slowdown in response time due to emotional conflict has been termed the congruency effect. 
Implicit emotion regulation is indexed by trial-to-trial changes in the congruency effect as a function of the congruency effect on the previous trial (trial $n-1$ ). Specifically, conflict on trial $n-1$ triggers an increase in emotional control, thereby reducing susceptibility to emotional conflict on trial $n$. Consistent with this, response times to incongruent-trials are usually faster after incongruent trials (iI) than after congruent trials (cI). Implicit emotion regulation is therefore indexed by contrasting response times on incongruent trials that are preceded by another incongruent trial (iI) with incongruent trails that are preceded by a congruent trial (cI), a behavioral effect shown to occur outside of awareness ${ }^{1}$.

Parallel studies of adaptation to non-emotional conflict (Egner et al., 2008) suggest that key elements of the neural circuitry involved in implicit regulation of emotional conflict is specific to emotional conflict. Specifically, neuroimaging studies of implicit emotion regulation, using the emotional conflict task, suggest a regulatory interplay between anterior cingulate cortex (ACC)/medial PFC, and emotion reactivity regions in the limbic system: increased activation in the ventral portion of the anterior cingulate (vACC), and dampened reactivity in the amygdala (Etkin et al., 2006; Etkin, Prater, Hoeft, Menon, \& Schatzberg, 2010). In the non-emotional analogue of the task, wherein subjects judged the gender of emotional faces while trying to ignore incongruent gender labels, regulation was achieved through a dissociable neural pathway, involving increased activation in the dorsolateral PFC, and positive coupling to target-specific visual cortical areas in the fusiform face area (Egner et al., 2008). Importantly, there was no evidence in the non-emotional conflict task of activation of the vACC or dampening of amygdalar reactivity (Egner et al., 2008).

This task fits our definition of implicit emotion regulation because the process is uninstructed, effortless and proceeds without awareness; despite careful probing, participants do not report any awareness of the key processes of the task (Etkin et al., 2010). The emotion regulation process described here is implicit: individuals are (a) unaware of the modulation of emotional control elicited by the stimuli on their behavior (i.e., response on iI vs. cI trials) and (b) the regulatory process is carried out largely outside of awareness.

\section{Habitual Emotion Regulation}

Absent explicit instructions, people report using emotion regulation fairly frequently on a daily basis (Gross, Richards, \& John, 2006). We suggest that the habitual pattern of engaged emotion regulatory strategies - whether assessed with retrospective self-report accounts or questionnaires - reflects a form of regulation that, depending on situational and personal factors, can fluctuate rapidly between the explicit and implicit domains. For example, one can explicitly remind oneself that an angry co-worker had a bad day to reduce frustration, and another time, one might engage in this reappraisal without any awareness. Furthermore, frequent use of a given explicit strategy can quickly render the initiation of the strategy more implicit during regulation, thus making it more implicit over time.

Gross and John (2003) examined habitual emotion regulation with a self-report questionnaire that measures individual differences in customary use of reappraisal and suppression. In a series of five studies, they showed that the habitual use of reappraisal was related to greater positive affect, better interpersonal functioning, and higher well-being. By contrast, greater use of suppression was related to a less beneficial profile of emotional functioning (Gross \& John, 2003). A recent neuroimaging study (Drabant, McRae, Manuck, Hariri, \& Gross, 2009) found that individuals who report using reappraisal as their preferred

\footnotetext{
${ }^{1}$ The trial-to-trial adaptation (iI-cI) index of emotion regulation is a variant of the full Gratton effect [(iI - cI) $\left.-(\mathrm{iC}-\mathrm{cC})\right]$. This adaptation effect is widely used in the cognitive regulation literature and constitutes a well-accepted measure of cognitive control. Furthermore, our studies indicate a selective deficit of iI-cI adaptation among patients with GAD (Etkin et al., 2010), a population characterized by severe emotion regulatory deficits.
} 
emotion regulatory strategy tend to engage prefrontal areas implicated in cognitive control, including reappraisal, more when they are looking at emotionally challenging negative faces. Similarly, Mauss and colleagues (Mauss, Cook, Cheng, \& Gross, 2007) reported that individuals high on reappraisal tendencies were able to regulate their emotions in the throes of powerful negative emotions (anger) and showed a more beneficial profile of physiological responding than their low reappraisal counterparts in response to an anger provocation.

Habitual use of emotion regulation is also related to individuals' implicit theories about emotions (Tamir, John, Srivastava, \& Gross, 2007) - that is, whether they view emotions as fixed (entity theorists), or as more malleable and thus "regulate-able" (incremental theorists). In a longitudinal study, Tamir and colleagues (Tamir et al., 2007) found that entity beliefs were related to lower emotion regulation self-efficacy perceptions and less use of cognitive reappraisal.

Habitual use of emotion regulation can also be seen in the unbidden emotion-regulatory attempts that participants, when prompted after conclusion of a laboratory-based emotion provocation, retrospectively report having used. For example, Egloff and colleagues (Egloff, Schmukle, Burns, \& Schwerdtfeger, 2006) showed that spontaneous recruitment of reappraisal and suppression during a stressful speech task results in similar experiential physiological and self-report effects as laboratory-induced use of reappraisal or suppression.

Another related line of work suggests that individuals' action orientation, defined as one's habitual tendency to respond to stress with decisive actions rather than to dwell on negative affect, might predispose individuals to quickly and effectively regulate their emotions (Koole \& Kuhl, 2008). Koole and colleagues (Jostmann, Koole, van der Wulp, \& Fockenberg, 2005; Koole \& Coenen, 2007; Koole \& Jostmann, 2004) argued that action orientation predisposes people to 'intuitively' regulate emotion and quickly decrease negative affect in demanding situations to facilitate higher order goal pursuit, even if emotions were triggered subliminally (Jostmann et al., 2005).

\section{Emotion Regulatory Goals and Values}

Emotion regulatory goals, values, and beliefs constitute another form of implicit regulation that routinely runs outside of awareness, but can be made explicit at times when these goals and values are articulated. Schweiger-Gallo and colleagues (Schweiger-Gallo, Keil, McCulloch, Rockstroh, \& Gollwitzer, 2009) documented a possible mechanism for the development of emotion regulatory goals. Specifically, they showed that automatizing goalpursuit by creating emotion regulation implementation intentions can serve as an effective way to regulate negative emotions. They furnished participants with implementation intentions (if-then plans that detail the process of goal attainment) and showed that these instructions through repeated practice reduced reactivity to accident-related threatening images (Schweiger-Gallo et al., 2009), and among spider-fearful individuals resulted in reduced reactivity. Taken together, these studies demonstrate the general tendency for implementation intentions to very quickly become routinized and automatized, and deploy with little subsequent awareness (Williams, Bargh, Nocera, \& Gray, 2009).

Once routinized, individual differences in attitudes toward emotion regulation can be assessed with reaction time tasks. Specifically, faster reaction time in categorizing emotionregulation related words as positive has been shown to relate to better regulation, and lower emotional reactivity in response to anger provocation (Mauss and colleagues (Mauss, Evers, Wilhelm, \& Gross, 2006). Activating control tendencies implicitly through priming seemed to confer similar benefits during anger provocation (Mauss, Cook, \& Gross, 2007), 
suggesting that automatic tendencies to control one's emotions aid regulation in "hot" anger provoking situations.

\section{Emotion Regulation as a Result of Affect Labeling}

A large body of work examined emotional processing in the context of certain intentional activities that have incidental/unintended emotion-regulation consequences. In one such paradigm, participants were instructed to either label an emotional face (e.g., indicate whether the face is angry or afraid) or to match the gender (Hariri, Bookheimer, \& Mazziotta, 2000; Lieberman et al., 2007; Lieberman, Hariri, Jarcho, Eisenberger, \& Bookheimer, 2005). Matching emotional expressions on faces with affect label words results in lower limbic system activation, including reduced activation in the amygdala, as compared to matching expressions to other expressions, matching the gender to gender labels, or to simply viewing the face. Similar to explicit forms of emotion regulation, labeling emotional faces or focusing on physical features of an emotionally evocative scene results in increased activation in the lateral and medial PFC, despite the fact that emotion regulation in this paradigm is unintentional or implicit (Hariri et al., 2000; Lieberman et al., 2005). Importantly, Lieberman and colleagues (Lieberman et al., 2007) report that the ventral portion of medial PFC activation mediates the relationship between lateral PFC activation and decreased amygdala activation, suggesting that, similar to implicit emotion regulation, it may be the medial PFC-amygdala pathway that plays a critical role in dampening emotional-reactivity in incidental forms of emotion-regulation.

\section{Error-related Regulation}

Our implicit emotion regulation task captures the ability to dynamically adapt control parameters in the context of emotionally conflicting stimuli and successfully carry over regulation from one trial to another. This adaptation process can be viewed as the ability of knowing when to "speed-up" in emotionally evocative contexts. The flip side of this phenomenon is the ability to "slow-down," or to adjust cognitive control following a failure in that same process. This post-error adjustment effect can be characterized at the level of reaction time (Rabbitt, 1966), or at the level of post-error accuracy (Laming, 1979). While error-related slowing in cognitive tasks is an active area of research using non-emotional stimuli, to our knowledge, no study has examined error-related slowing and error-related accuracy in the context of emotionally challenging stimuli. Nonetheless, errors themselves are negative emotional events, as evidenced by increased activation of the defensive motivational system following errors (Hajcak \& Foti, 2008).

Scalp EEG studies and intracranial recordings show that error related processing is marked by the presence of a characteristic negative deflection, called the Error Related Negativity (ERN) and is dependent on the interplay between cognitive areas (ACC) and emotional (amygdala) brain regions (Olvet \& Hajcak, 2008; Pourtois et al., 2010). Furthermore, the size of the ERN has been studied as a marker of emotion regulation abilities in children (Dennis \& Hajcak, 2009) and shown to be related to psychopathology characterized by emotion dysregulation (Holmes \& Pizzagalli, 2008; Olvet \& Hajcak, 2008; Pizzagalli, Peccoralo, Davidson, \& Cohen, 2006). Furthermore, and in line with the functional properties of post-error adjustment, Robinson and colleagues found that greater error-related slowing is associated with greater wellbeing (M. D. Robinson, 2007) and better stressregulation abilities (Compton et al., 2008).

Collectively, these studies argue that efficient post-error adjustment depends on an interplay between cognitive and emotional areas. Illustrating the complexity of implicitness in this work, research shows that the behavioral marker of error-related slowing is more strongly 
associated with consciously perceived errors, but that ERN is detectable after both conscious and non-conscious errors (Nieuwenhuis, Ridderinkhof, Blom, Band, \& Kok, 2001).

\section{Future Directions}

As our targeted survey of the emotion regulation literature suggests, there are a large number of compelling directions for future research. In the following sections, we detail some of the directions we believe may be most fruitful in clarifying explicit and implicit qualities of each research domain.

\section{Measurement}

Research on implicit emotion regulation has grown by leaps and bounds in recent years, raising important questions about the measurement and operationalization of these processes. We know from existing research that conscious deployment of emotion regulation can reliably and positively shape the course of emotional responses, but it is less clear whether deploying and executing regulation without awareness can have similar benefits. We also expect future research to assess whether understanding the temporal unfolding of an emotional response will help conceptually organize implicit emotion regulation in the way that it has for explicit regulation (Gross \& Thompson, 2007). Finally, another important issue is whether the effects of implicit emotion regulation can be measured on subjective experience without perturbing the process.

As suggested by the studies cited above, there is growing evidence that explicit regulation involves lateral PFC regulatory sites, while at least some forms of implicit regulation involves vACC or medial PFC sites (Phillips, Ladouceur \& Drevets, 2008). At the same time, the affect labeling studies suggest that implicit regulation can involve lateral PFC systems (e.g., Lieberman et al., 2007). Both the medial and later PFC have been broadly associated with goal-directed behaviors, deliberate actions, and executive functioning (e.g., Miller \& Cohen 2001), but it is not clear whether activation in this area is uniquely associated with either explicit or implicit forms of emotion regulation, or rather, as part of a regulatory network, the neural source of regulation that is dependent on task context.

\section{Functional Consequences}

A growing body of evidence suggests that contextually appropriate and flexible use of emotion regulation may be a marker of mental health. For example, explicit emotion regulation, particularly cognitive reappraisal, has been shown to result in lower physiological reactivity and less intense emotional experiences than suppression (Gross, 1998b, 2002) and has also been related to lower self-reported emotions in a lab stress and better functional life outcomes in an at-risk sample of distressed community women (Troy, Wilhelm, Shallcross \& Mauss, in press). Better performance (less emotional behavior) on a task of emotional suppression in two different studies has been related to higher well-being and socio-economic status, suggesting that the ability to implement emotion-regulation following explicit instructions might be related to broader measures of positive life outcomes (Côté, Gyurak, \& Levenson, in press). Research suggests that implicit emotion regulation represents a similarly adaptive process. There is evidence of marked implicit emotion regulatory deficits in Generalized Anxiety Disorder (GAD; Etkin et al., 2010). Importantly, failure to engage implicit emotion regulatory processes is related to symptom severity in this group, suggesting that implicit emotion regulatory performance is related to adaptive functional outcomes.

In future work, it will be important to study explicit and implicit emotion regulation in different forms of psychopathology. Specifically, previous studies suggest that the root of emotion regulatory difficulties in psychopathology, particularly in the anxiety or mood 
domain, might be in more spontaneous, implicit forms of emotion regulation (e.g., Ehring, Tuschen-Caffier, Schnülle, Fischer, \& Gross, in press; Etkin et al., 2010), but this hypothesis needs to be more extensively tested. Additionally, psychopathology may be characterized not only by a failure to use emotion regulation appropriately, but also by inflexible use of emotion regulation, as exemplified by the role of worry in GAD (Borkovec, Alcaine, \& Behar 2004). More research is needed to clarify the role of implicit processes in psychopathology.

\section{Training and Modifying Emotion Regulation}

Another important area for future research is to explore ways in which explicit forms of regulation can be made more implicit and vice-versa. For example, one way in which explicit regulatory processes may be made more implicit (and hence potentially more resource efficient) is through practice. For example, explicit learning of an emotion regulation-related skill might render that skill implicit after sufficient repetition and mastery. There is evidence that intervening early in the emotion generative process through repeated training of attention allocation away from negative stimuli and toward neutral stimuli has proven effective in reducing symptoms and improving functioning in patients with psychiatric disorders (e.g., Hakamata et al., 2010). Similarly Tran and colleagues (Tran, Siemer, \& Joorman, 2010) show that inducing automatic negative interpretative biases in a single training session resulted in heightened reactivity and lower self-esteem following negative feedback. These results indicate that implicit biases can be altered via repetitive training, as well as one-time manipulations, though additional research is necessary to determine the extent to which these interventions target emotion regulation per se.

\section{Concluding Comment}

It is now firmly established that willfully- and consciously-employed emotion regulatory strategies can reliably alter the course of emotional responding, but it is also apparent that people do not and will not pursue conscious regulatory goals unless they have the motivation and the ability to do so. Additionally, because of emotions are quick and fastchanging phenomena, emotion regulation in its implicit forms has the advantage of being more efficient and effortless than explicit regulation. Implicit processes in general are much more consistent and reliable (is also sometimes less flexible), as they are triggered automatically and run to completion without conscious effort or monitoring. A complete understanding of emotion regulation and its role in mental health thus requires a detailed investigation of implicit forms of regulation. It is our hope that the dual-process theoretical framework presented here will serve as a systematizing and organizing basis for future work.

\section{Acknowledgments}

The authors would like to thank Sander Koole, Klaus Rothermund, two anonymous reviewers, the members of the Stanford Psychophysiology Lab and the Etkin Lab for their helpful comments and suggestions with this paper.

\section{References}

Banks SJ, Eddy KT, Angstadt M, Nathan PJ, Phan KL. Amygdala-frontal connectivity during emotion regulation. Social Cognitive and Affective Neuroscience. 2007; 2(4):303-312. [PubMed: 18985136]

Bargh, JA. The four horsemen of automaticity: Awareness, intention, efficiency, and control in social cognition. In: Wyer, Robert S., Jr; Srull, Thomas K., editors. Handbook of social cognition, Vol. 1: Basic processes. 1994.

Bargh, JA.; Williams, LE. The Nonconscious regulation of emotion. In: Gross, James J., editor. Handbook of emotion regulation. New York, NY, US: Guilford Press; 2007. p. 429-445.p. xvii 
Beauregard M, Lévesque J, Bourgouin P. Neural correlates of conscious self-regulation of emotion. The journal of neuroscience. 2001; 21(18):RC165. [PubMed: 11549754]

Borkovec, TD.; Alcaine, OM.; Behar, E. Avoidance theory of worry and Generalized Anxiety Disorder. In: Heimberg, Richard G.; Turk, Cynthia L.; Mennin, Douglas S., editors. Generalized anxiety disorder: Advances in research and practice. Vol. 2004. 2004.

Botvinick M, Nystrom LE, Fissell K, Carter CS, Cohen JD. Conflict monitoring versus selection-foraction in anterior cingulate cortex. Nature. 1999; 402(6758):179-181.10.1038/46035 [PubMed: 10647008]

Campos JJ, Campos RG, Barrett KC. Emergent themes in the study of emotional development and emotion regulation. Developmental Psychology. 1989; 25(3):394-402.

Cole PM, Martin SE, Dennis TA. Emotion regulation as a scientific construct: methodological challenges and directions for child development research. Child Development. 2004; 75(2):317333. [PubMed: 15056186]

Compton RJ, Robinson MD, Ode S, Quandt LC, Fineman SL, Carp J. Error-monitoring ability predicts daily stress regulation. Psychological Science. 2008; 19(7):702-708. [PubMed: 18727786]

Côté S, Gyurak A, Levenson RW. The ability to implement emotion regulation is associated with greater well-being, income, and socioeconomic status. Emotion. (in press).

Demaree HA, Schmeichel BJ, Robinson JL, Pu J, Everhart DE, Berntson GG. Up- and downregulating facial disgust: Affective, vagal, sympathetic, and respiratory consequences. Biological psychology. 2006; 71(1):90-99. [PubMed: 15970372]

Dennis TA, Hajcak G. The late positive potential: a neurophysiological marker for emotion regulation in children. Journal of Child Psychology and Psychiatry. 2009; 50(11):1373-1383.10.1111/j. 1469-7610.2009.02168.x [PubMed: 19754501]

Drabant EM, McRae K, Manuck SB, Hariri AR, Gross JJ. Individual differences in typical reappraisal use predict amygdala and prefrontal responses. Biological Psychiatry. 2009; 65(5):367-373. [PubMed: 18930182]

Egloff B, Schmukle SC, Burns LR, Schwerdtfeger A. Spontaneous Emotion Regulation During Evaluated Speaking Tasks: Associations with Negative Affect, Anxiety Expression, Memory, and Physiological Responding. Emotion. 2006; 6(3):356-366. [PubMed: 16938078]

Egner T, Etkin A, Gale S, Hirsch J. Dissociable neural systems resolve conflict from emotional versus nonemotional distracters. Cerebral cortex (New York, NY: 1991). 2008; 18(6):1475-1484.

Ehring T, Tuschen-Caffier B, Schnülle J, Fischer S, Gross JJ. Emotion regulation and vulnerability to depression: Spontaneous versus instructed use of emotion suppression and reappraisal. Emotion. (in press).

Eippert F, Veit R, Weiskopf N, Erb M, Birbaumer N, Anders S. Regulation of emotional responses elicited by threat-related stimuli. Human Brain Mapping. 2007; 28(5):409-423. [PubMed: 17133391]

Eisenberg N, Fabes RA, Guthrie IK, Reiser M. Dispositional emotionality and regulation: their role in predicting quality of social functioning. Journal of personality and social psychology. 2000; 78(1): 136-157. [PubMed: 10653511]

Etkin A, Egner T, Peraza DM, Kandel ER, Hirsch J. Resolving emotional conflict: a role for the rostral anterior cingulate cortex in modulating activity in the amygdala. Neuron. 2006; 51(6):871-882. [PubMed: 16982430]

Etkin A, Prater KE, Hoeft F, Menon V, Schatzberg AF. Failure of anterior cingulate activation and connectivity with the amygdala during implicit regulation of emotional processing in generalized anxiety disorder. The American Journal of Psychiatry. 2010

Freud, A. The Ego and the Mechanisms of Defense: The Writings of Anna Freud. Vol. 2. International Universities Press; 1936. (Revised.)

Freud, S. Inhibitions, Symptoms and Anxiety (The Standard Edition). W. W. Norton \& Company; 1926.

Frijda, NH. The Emotions. Cambridge University Press; 1987. (Reprint.)

Goldin PR, McRae K, Ramel W, Gross JJ. The neural bases of emotion regulation: reappraisal and suppression of negative emotion. Biological Psychiatry. 2008; 63(6):577-586. [PubMed: 17888411] 
Gratton G, Coles MG, Donchin E. Optimizing the use of information: strategic control of activation of responses. Journal of Experimental Psychology. General. 1992; 121(4):480-506. [PubMed: 1431740]

Gross JJ. The emerging field of emotion regulation: An integrative review. Review of General Psychology. Special Issue: New directions in research on emotion. 1998a; 2(3):271-299.

Gross JJ. Antecedent- and response-focused emotion regulation: divergent consequences for experience, expression, and physiology. Journal of Personality and Social Psychology. 1998b; 74(1):224-237. [PubMed: 9457784]

Gross JJ, John OP. Individual differences in two emotion regulation processes: Implications for affect, relationships, and well-being. Journal of Personality and Social Psychology. 2003; 85(2):348-362. [PubMed: 12916575]

Gross JJ, Levenson RW. Emotional suppression: physiology, self-report, and expressive behavior. Journal of Personality and Social Psychology. 1993; 64(6):970-986. [PubMed: 8326473]

Gross, JJ.; Thompson, RA. Emotion Regulation: Conceptual Foundations. In: Gross, James J., editor. Handbook of emotion regulation. Vol. 2007. New York, NY, US: Guilford Press; 2007. p. 3-24.

Gross JJ, Carstensen LL, Pasupathi M, Tsai J, Skorpen CG, Hsu AY. Emotion and aging: experience, expression, and control. Psychology and Aging. 1997; 12(4):590-599. [PubMed: 9416628]

Gross, JJ.; Richards, JM.; John, OP. Emotion Regulation in Everyday Life. In: Snyder, Douglas K.; Simpson, Jeffry; Hughes, Jan N., editors. Emotion regulation in couples and families: Pathways to dysfunction and health. Vol. 2006. Washington, DC, US: American Psychological Association; 2006. p. 13-35.

Hajcak G, Foti D. Errors are aversive: defensive motivation and the error-related negativity. Psychological Science: A Journal of the American Psychological Society/APS. 2008; 19(2):103108.10.1111/j.1467-9280.2008.02053.x

Hakamata Y, Lissek S, Bar-Haim Y, Britton JC, Fox NA, Leibenluft E, Ernst M, et al. Attention Bias Modification Treatment: A Meta-Analysis Toward the Establishment of Novel Treatment for Anxiety. Biological Psychiatry. 201010.1016/j.biopsych.2010.07.021

Hariri AR, Bookheimer SY, Mazziotta JC. Modulating emotional responses: effects of a neocortical network on the limbic system. Neuroreport. 2000; 11(1):43-48. [PubMed: 10683827]

Herwig U, Baumgartner T, Kaffenberger T, Brühl A, Kottlow M, Schreiter-Gasser U, Abler B, et al. Modulation of anticipatory emotion and perception processing by cognitive control. NeuroImage. 2007; 37(2):652-662. [PubMed: 17588776]

Holmes AJ, Pizzagalli DA. Spatiotemporal dynamics of error processing dysfunctions in major depressive disorder. Archives of General Psychiatry. 2008; 65(2):179-188. [PubMed: 18250256]

Jostmann NB, Koole SL, van der Wulp NY, Fockenberg DA. Subliminal Affect Regulation: The Moderating Role of Action vs. State Orientation. European Psychologist. 2005; 10(3):209-217.

Kalisch R. The functional neuroanatomy of reappraisal: time matters. Neuroscience and Biobehavioral Reviews. 2009; 33(8):1215-1226. [PubMed: 19539645]

Kalisch R, Wiech K, Critchley HD, Seymour B, O’Doherty JP, Oakley DA, Allen P, et al. Anxiety reduction through detachment: subjective, physiological, and neural effects. Journal of Cognitive Neuroscience. 2005; 17(6):874-883. [PubMed: 15969906]

Kalisch R, Wiech K, Herrmann K, Dolan RJ. Neural correlates of self-distraction from anxiety and a process model of cognitive emotion regulation. Journal of Cognitive Neuroscience. 2006; 18(8): 1266-1276. [PubMed: 16859413]

Kim SH, Hamann S. Neural correlates of positive and negative emotion regulation. Journal of Cognitive Neuroscience. 2007; 19(5):776-798. [PubMed: 17488204]

Koole, SL. The psychology of emotion regulation: An integrative review. In: De Houwer, Jan; Hermans, Dirk, editors. Cognition and emotion: Reviews of current research and theories. Vol. 2010. 2010.

Koole SL, Coenen LHM. Implicit self and affect regulation: Effects of action orientation and subliminal self priming in an affective priming task. Self and Identity. 2007; 6(2-3):118-136.

Koole SL, Jostmann NB. Getting a grip on your feelings: effects of action orientation and external demands on intuitive affect regulation. Journal of Personality and Social Psychology. 2004; 87(6): 974-990.10.1037/0022-3514.87.6.974 [PubMed: 15598118] 
Koole, SL.; Kuhl, J. Dealing with unwanted feelings: The role of affect regulation in volitional action control. In: Shah, James Y.; Gardner, Wendi L., editors. Handbook of motivation science. Vol. 2008. New York, NY, US: Guilford Press; 2008. p. 295-307.p. xviii

Kunzmann U, Kupperbusch CS, Levenson RW. Behavioral inhibition and amplification during emotional arousal: a comparison of two age groups. Psychology and Aging. 2005; 20(1):144-158. [PubMed: 15769220]

Laming D. Autocorrelation of choice-reaction times. Acta Psychologica. 1979; 43(5):381-412. [PubMed: 495175]

Lazarus, RS.; Folkman, S. Stress, Appraisal, and Coping. Springer Publishing Company; 1984.

Levenson RW. The intrapersonal functions of emotion. Cognition \& Emotion. Special Functional accounts of emotion. 1999; 13(5):481-504.

Levesque J, Eugène F, Joanette Y, Paquette V, Mensour B, Beaudoin G, Leroux J, et al. Neural circuitry underlying voluntary suppression of sadness. Biological Psychiatry. 2003; 53(6):502510. [PubMed: 12644355]

Lewis MD, Lamm C, Segalowitz SJ, Stieben J, Zelazo PD. Neurophysiological Correlates of Emotion Regulation in Children and Adolescents. Journal of cognitive neuroscience. 2006; 18(3):430-443. [PubMed: 16513007]

Lieberman MD, Eisenberger NI, Crockett MJ, Tom SM, Pfeifer JH, Way BM. Putting feelings into words: affect labeling disrupts amygdala activity in response to affective stimuli. Psychological Science: A Journal of the American Psychological Society/APS. 2007; 18(5):421-428.

Lieberman MD, Hariri AR, Jarcho JM, Eisenberger NI, Bookheimer SY. An fMRI investigation of race-related amygdala activity in African-American and Caucasian-American individuals. Nature Neuroscience. 2005; 8(6):720-722.10.1038/nn1465

Mauss IB, Cook CL, Gross JJ. Automatic emotion regulation during anger provocation. Journal of Experimental Social Psychology. 2007; 43(5):698-711.

Mauss IB, Cook CL, Cheng JYJ, Gross JJ. Individual differences in cognitive reappraisal: experiential and physiological responses to an anger provocation. International Journal of Psychophysiology: Official Journal of the International Organization of Psychophysiology. 2007; 66(2):116-124. [PubMed: 17543404]

Mauss IB, Evers C, Wilhelm FH, Gross JJ. How to bite your tongue without blowing your top: implicit evaluation of emotion regulation predicts affective responding to anger provocation. Personality and Social Psychology Bulletin. 2006; 32(5):589-602. [PubMed: 16702153]

McRae K, Hughes B, Chopra S, Gabrieli JDE, Gross JJ, Ochsner KN. The neural bases of distraction and reappraisal. Journal of Cognitive Neuroscience. 2010; 22(2):248-262. [PubMed: 19400679]

Miller EK, Cohen JD. An integrative theory of prefrontal cortex function. Annual Review of Neuroscience. 2001; 24:167-202.

Moors A, De Houwer J. Automaticity: A Theoretical and Conceptual Analysis. Psychological Bulletin. 2006; 132(2):297-326. [PubMed: 16536645]

Nieuwenhuis S, Ridderinkhof KR, Blom J, Band GP, Kok A. Error-related brain potentials are differentially related to awareness of response errors: evidence from an antisaccade task. Psychophysiology. 2001; 38(5):752-760. [PubMed: 11577898]

Ochsner KN, Gross JJ. The cognitive control of emotion. Trends in cognitive sciences. 2005; 9(5): 242-249. [PubMed: 15866151]

Ochsner KN, Bunge SA, Gross JJ, Gabrieli JDE. Rethinking feelings: An fMRI study of the cognitive regulation of emotion. Journal of cognitive neuroscience. 2002; 14(8):1215-1229. [PubMed: 12495527]

Olvet D, Hajcak G. The error-related negativity (ERN) and psychopathology: Toward an endophenotype. Clinical Psychology Review. 2008; 28(8):1343-1354.10.1016/j.cpr.2008.07.003 [PubMed: 18694617]

Phillips ML, Ladouceur CD, Drevets WC. A neural model of voluntary and automatic emotion regulation: implications for understanding the pathophysiology and neurodevelopment of bipolar disorder. Molecular Psychiatry. 2008; 13(9):833-857. 
Pizzagalli DA, Peccoralo LA, Davidson RJ, Cohen JD. Resting anterior cingulate activity and abnormal responses to errors in subjects with elevated depressive symptoms: a 128-channel EEG study. Human Brain Mapping. 2006; 27(3):185-201.10.1002/hbm.20172 [PubMed: 16035102]

Posner, MI.; Rothbart, MK. Annual progress in child psychiatry and child development: 2000-2001; Annual progress in child psychiatry and child development: 2000-2001. New York, NY, US: Brunner-Routledge; 2003. Developing mechanisms of self-regulation; p. 21-42.

Pourtois G, Vocat R, N'Diaye K, Spinelli L, Seeck M, Vuilleumier P. Errors recruit both cognitive and emotional monitoring systems: Simultaneous intracranial recordings in the dorsal anterior cingulate gyrus and amygdala combined with fMRI. Neuropsychologia. 2010; 48(4):11441159.10.1016/j.neuropsychologia.2009.12.020 [PubMed: 20026086]

Rabbitt PM. Errors and error correction in choice-response tasks. Journal of Experimental Psychology. 1966; 71(2):264-272. [PubMed: 5948188]

Ray RD, Ochsner KN, Cooper JC, Robertson ER, Gabrieli JDE, Gross JJ. Individual differences in trait rumination and the neural systems supporting cognitive reappraisal. Cognitive, Affective \& Behavioral Neuroscience. 2005; 5(2):156-168.

Robinson MD. Gassing, braking, and self-regulating: Error self-regulation, well-being, and goalrelated processes. Journal of experimental social psychology. 2007; 43(1):1-16.

Schweiger-Gallo I, Keil A, McCulloch KC, Rockstroh B, Gollwitzer PM. Strategic automation of emotion regulation. Journal of Personality and Social Psychology. 2009; 96(1):11-31. [PubMed: 19210061]

Stroop JR. Studies of interference in serial verbal reactions. Journal of experimental psychology. 1935; 18(6):643-662.

Tran BT, Siemer M, Joorman J. Implicit Interpretation Biases Affect Emotional Vulnerability. Cognition and Emotion. (this issue).

Troy A, Wilhelm FH, Shallcross A, Mauss IB. Seeing the silver Lining: cognitive reappraisal ability moderates the relationship between stress and depressive symptoms. Emotion. (in press).

Urry HL. Seeing, thinking, and feeling: emotion-regulating effects of gaze-directed cognitive reappraisal. Emotion. 2010; 10(1):125-135. [PubMed: 20141309] 


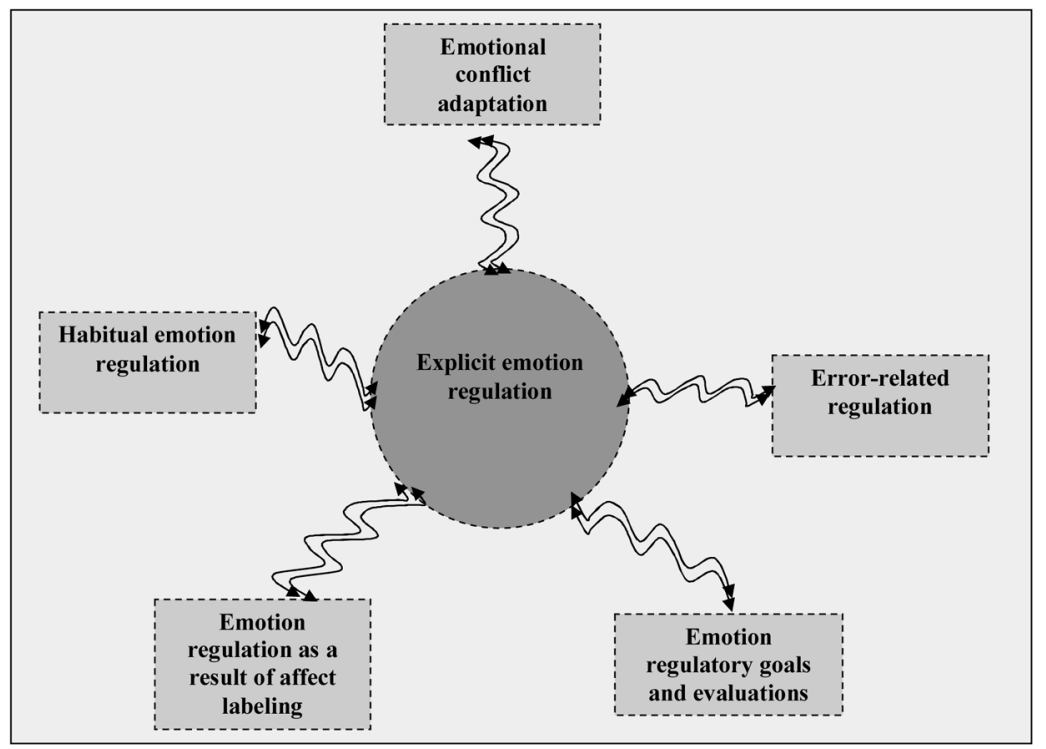

Figure 1.

A dual-process model of emotion regulation. Explicit emotion regulation processes are depicted in the center. Everything outside this circle represents processes that are related to implicit emotion regulation. 
Explicit emotion regulation $=$

(Mean emotional response during react naturally to negative) -

(Mean emotional response during regulate to negative).

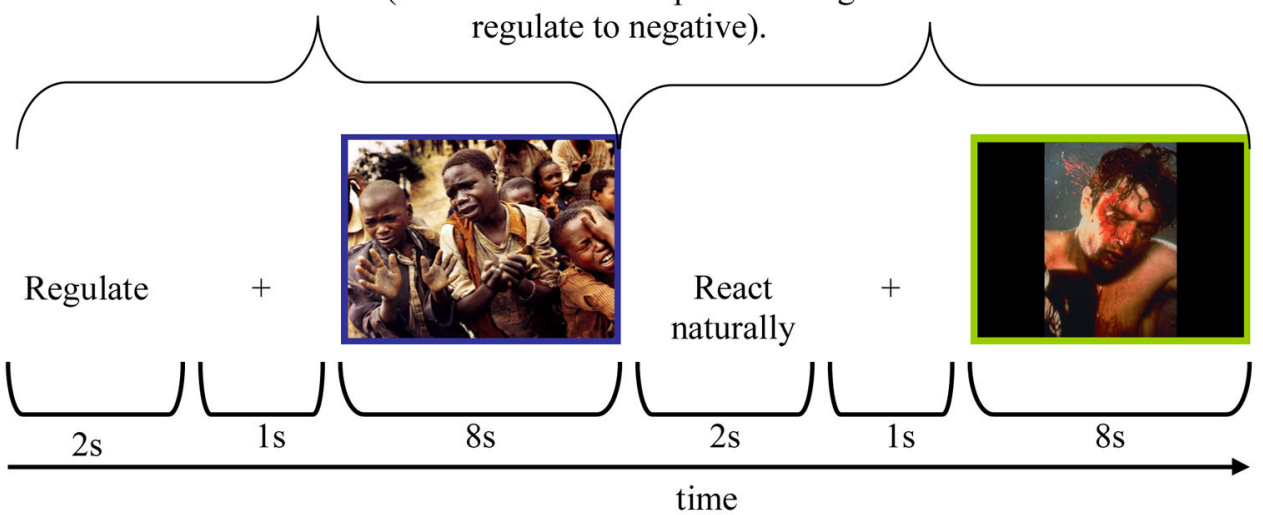

Figure 2.

Schematic depiction of an explicit emotion regulation task modeled after McRae et al. (2010). Explicit emotion regulation performance is indexed by contrasting emotional responding in the reactivity and regulation trials. 


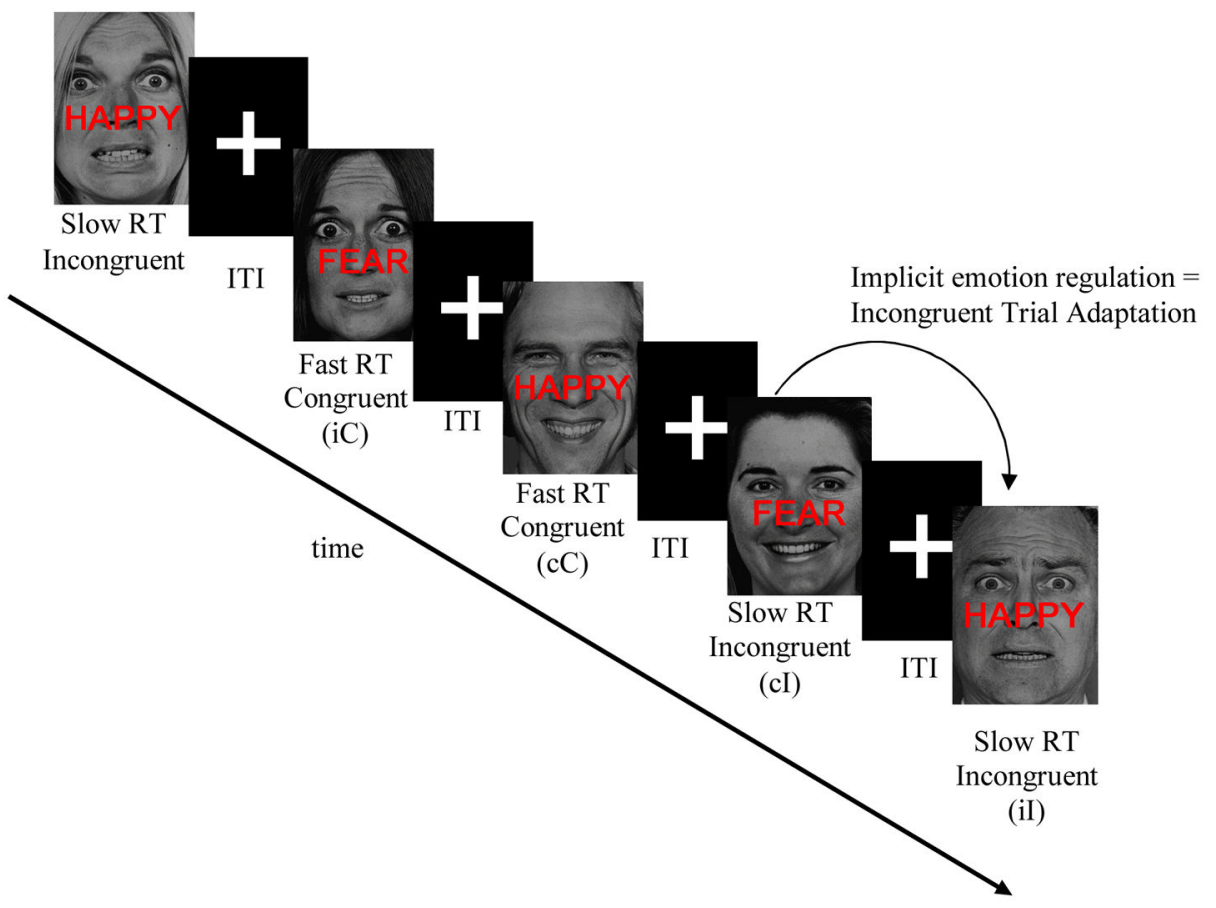

Figure 3.

Schematic depiction of the implicit emotion regulation task modeled after Etkin et al., (2006). ITI = Inter Trial Interval. RT = response time. 